\title{
Systemic arterial supply to normal basal segments of the left lower lobe along with the pulmonary artery: Is lung resection warranted?
}

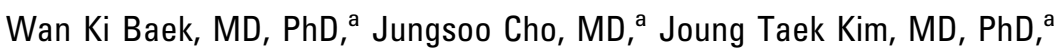
Yong Han Yoon, MD, ${ }^{a}$ Kwang Ho Kim, MD, ${ }^{a}$ Hyun Kyoung Lim, MD, ${ }^{\mathrm{b}}$ Lucia Kim, MD, PhD, ${ }^{\mathrm{c}}$ and Hong-Lyoel Lee, MD, PhD, ${ }^{d}$ Incheon, South Korea

everal reports that describe anomalous systemic arterial supply to the basal segments of the left lung without sequestration uniformly state absence of the pulmonary artery in the diseased segments of the lung. The surgical treatment encompasses ligation or division of the anomalous artery, routinely followed by resection of the diseased segments of the lung or reimplantation of the anomalous artery to the pulmonary artery. We report here a case of systemic arterial supply to the basal segments of the left lower lobe along with the pulmonary artery and normal tracheobronchial tree. In this particular case, simple division of the anomalous artery has brought a satisfactory result. No lung resection or reimplantation of the anomalous artery was warranted.

From the Departments of Thoracic and Cardiovascular Surgery, ${ }^{\text {a }}$ Anesthesiology, ${ }^{\mathrm{b}}$ and Pathology ${ }^{\mathrm{c}}$ and the Division of Pulmonology, ${ }^{\mathrm{d}}$ Inha University Hospital, Incheon, South Korea.

Received for publication Sept 13, 2005; accepted for publication Oct 10, 2005.

Address for reprints: Wan Ki Baek, MD, PhD, Department of Thoracic and Cardiovascular Surgery, Inha University Hospital, 7-206, 3-Ga, ShinheungDong, Jung-Ku, Incheon 400-103, South Korea (E-mail: wkbaek@ inha.ac.kr).

J Thorac Cardiovasc Surg 2006;131:742-3

$0022-5223 / \$ 32.00$

Copyright $\odot 2006$ by The American Association for Thoracic Surgery doi:10.1016/j.jtcvs.2005.10.053

\section{Clinical Summary}

A 17-year-old boy presented with recurrent episodes of hemoptysis.

He had been taking empiric antituberculous medication for 6 months. A computed tomographic scan was obtained that demonstrated a large anomalous systemic artery from the descending aorta to the lower part of the left lung. An aortogram confirmed the artery supplying the basal segments of the left lower lobe (Figure 1). The presence of normal pulmonary artery supplying the basal segments was not certain, although the pulmonary arteriogram was closely reviewed. Bronchoscopy revealed no evidence of sequestration of the lung. Lung scanning showed a matched perfusion defect on the left lower lobe.

The operation was performed through a left posterolateral thoracotomy. The surface of the basal segments was telangiectatic with capillary dilatations and was easily distinguished from other normal parts of the lung (Figure 2, A). The anomalous artery was seen originating from the anterolateral aspect of the descending aorta, about $3 \mathrm{~cm}$ below the level of left lower pulmonary vein, measuring $1 \mathrm{~cm}$ in diameter (Figure 2, B). On dissecting the fissure, intact pulmonary arteries to the basal segments were unexpectedly seen. The original plan to resect the diseased segments of the lung was modified. The anomalous systemic artery was dissected and temporarily occluded with a clamp. After confirming that there was no remarkable change of the color and shape of the diseased segments of the lung, as
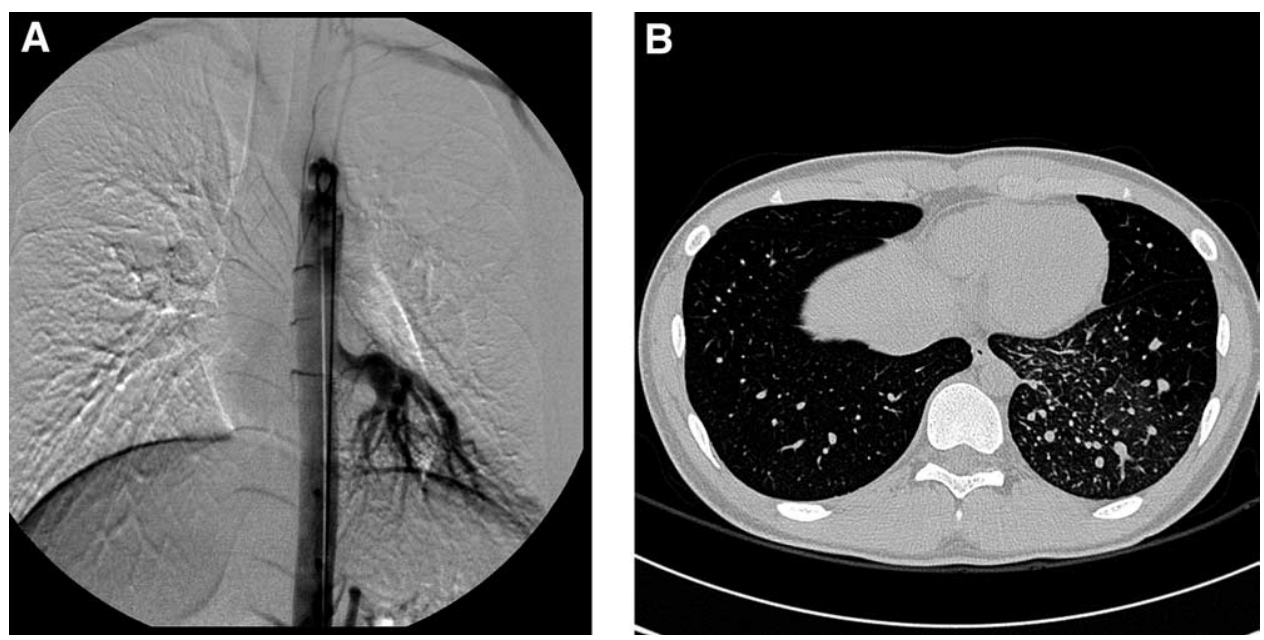

Figure 1. A: Aortogram showing a large anomalous artery from the ascending aorta supplying the basal segments of the left lower lobe. B: Chest CT showing clearly deamarcated area supplied by an anomalous artery, characterized by vascular crowding and increased interstitial density. 

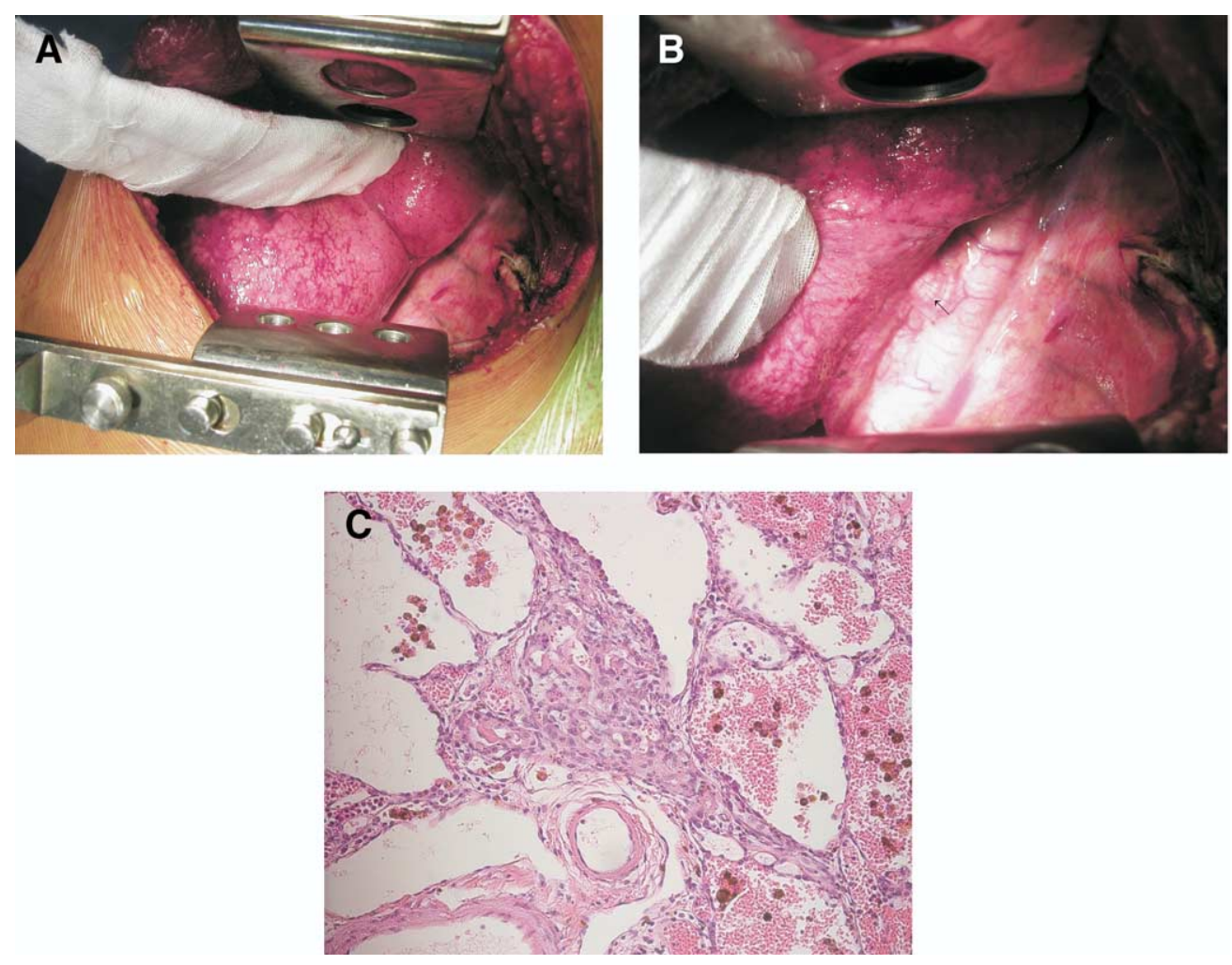

Figure 2. A, The surface of the basal segments was telangiectatic with capillary dilatations and was easily distinguished from other normal part of the lung. B, The anomalous artery was seen originating from the anterolateral aspect of the descending aorta, about $3 \mathrm{~cm}$ below the level of the left lower pulmonary vein, measuring $1 \mathrm{~cm}$ in diameter. C, Histopathologic examination of the biopsy specimen taken from the diseased segment suggested irreversible vascular disease.

well as hemodynamics and blood gases, the artery was divided with a vascular stapler.

Recovery was uneventful, and the patient was sent home on the fifth postoperative day. Although histopathologic examination of the biopsy specimen taken from the diseased segment suggested an irreversible vascular disease (Figure 2,C), improvement of the perfusion in basal segments was documented by the lung scan a year after, and the patient is doing well without recurrence of hemoptysis or pulmonary infection.

\section{Discussion}

Anomalous systemic artery supply to the normal basal segments of the left lower lobe was recently reviewed by Yamanaka and associates, ${ }^{1}$ with a report of their own 4 cases. Their total number of cases reached 12, with an almost uniform pattern of disease; the anomalous artery is originating from the descending aorta to the left basal segments, and the corresponding pulmonary artery to the segments of the lung is lacking. Resection of the diseased segments of the lung was a standard surgical treatment, with the exception of 2 cases of reimplantation of anomalous artery to the pulmonary artery. Later, Iizasa and colleagues ${ }^{2}$ added 4 cases, reporting a similar surgical result. They mentioned that in cases of dual blood supply of lung tissue from both the systemic and pulmonary artery, simple ligation and interruption of the abnormal flow would suffice. However, in reality, dual blood supply in this particular group of patients characterized by the typical angiographic features of an anomalous artery originating from the descending aorta above the diaphragm and supplying basal segments of the left lower lobe has rarely been described. We could find only one case of surgical ligation in a 14-month-old baby from the literature. ${ }^{3}$ In the adult age group this would be the first report of successful surgical treatment, leaving diseased lung segments intact. The presence of normal pulmonary artery to the diseased segments of the lung was hard to define by means of pulmonary angiography, largely because of flows from the anomalous artery. Although the pathology of lung tissue was deemed to reveal irreversible damage, the symptom disappeared completely after the operation, and the improvement of lung function was documented by the lung scan a year after.

\section{References}

1. Yamanaka A, Hirai T, Fujimoto T, Hase M, Noguchi M, Konishi F. Anomalous systemic arterial supply to normal basal segments of the left lower lobe. Ann Thorac Surg. 1999;68:332-8.

2. Iizasa T, Haga Y, Hiroshima K, Fujisawa T. Systemic arterial supply to the basal segments without pulmonary artery: four consecutive cases. Eur J Cardiothorac Surg. 2003;23:847-9.

3. Campbell DC Jr, Murney JA, Dominy DE. Systemic arterial blood supply to a normal lung. JAMA. 1962;182:497-9. 